\title{
TRANSITION METAL COMPLEXES OF PORPHINS, CORRINS AND RELATED COMPOUNDS
}

\author{
A. W. JOHNSON \\ School of Molecular Sciences, University of Sussex, Falmer, \\ Brighton, BN1 $9 Q J$
}

\begin{abstract}
The group of macrocyclic tetrapyrrolic ligands which includes the porphins, chlorins and corrins, occur in several biologically important molecules in the form of metal complexes. Intermediate in structure between the porphins and the corrins are the corroles and the 1-monosubstituted-, and 1,19-disubstituted tetradehydrocorrins. Syntheses and reactions of metal, particularly nickel, complexes of these novel ring systems are described.

The vitamin $\mathrm{B}_{12}$ coenzyme, which is a cobalt-corrin derivative containing adenosine bound to the cobalt through a 5 -carbon-cobalt covalent bond, is considered in the light of this unique structural feature. The mode of biosynthesis of the coenzyme can be partially simulated in the laboratory and a brief survey of the biochemical reactions controlled by the coenzyme is given.
\end{abstract}

The recognition of the structures of the vital transition metal complexes haemin(I) and chlorophyll(II) ${ }^{1}$ gave an important biological impetus to organometallic chemistry in its very early days, and at the same time initiated a detailed study of the precise function, in chemical terms, of these and other organometallic compounds in Nature ${ }^{2}$. Both haemin and chlorophyll are derivatives of the ligand porphin(III), the addition of the two extra $\beta$-hydrogen atoms in chlorophyll causing the red-brown colour of haemin to be modified to green in the dihydroporphin or chlorin. Porphin is a typically aromatic heterocyclic containing $18 \pi$-electrons in its extended conjugated system as well as having the four nitrogen atoms ideally arranged for square planar or octahedral coordination with metals. A wide range of these have been utilized in the formation of porphin complexes, rhodium $^{3}$, ruthenium $^{4}$, iridium $^{5}$, and gold $^{6}$ being relatively new additions, all from Fleischer's laboratory, while germanium ${ }^{7}$ and volatile silicon derivatives ${ }^{8}$ are examples of non-transition complexes recently described.

Meanwhile a third natural product, the vitamin $\mathbf{B}_{12}$ coenzyme(IV), has been isolated, and shown by $x$-ray crystallography ${ }^{9}$ to contain the corrin ring(V) as the chromophoric ligand, as well as a $5^{\prime}$-deoxyadenosyl group attached directly to cobalt through a cobalt-carbon bond. Our interest in the naturally occurring metallic porphins and corrins ${ }^{10}$ has led us to examine a number of properties of these and related ring systems but at the outset of 
A. W. JOHNSON
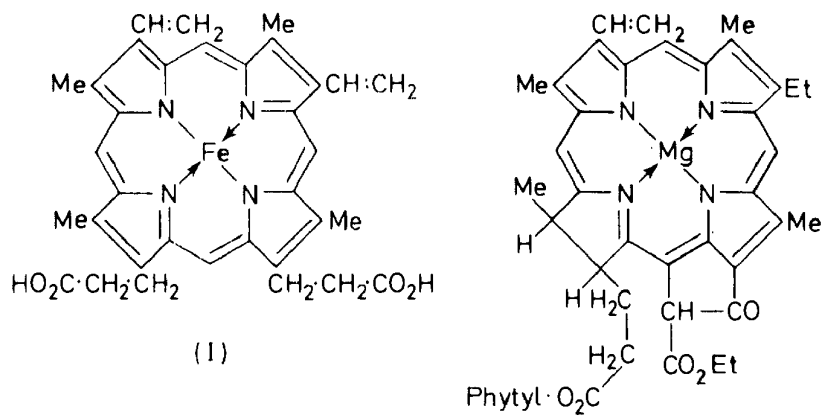

(1)
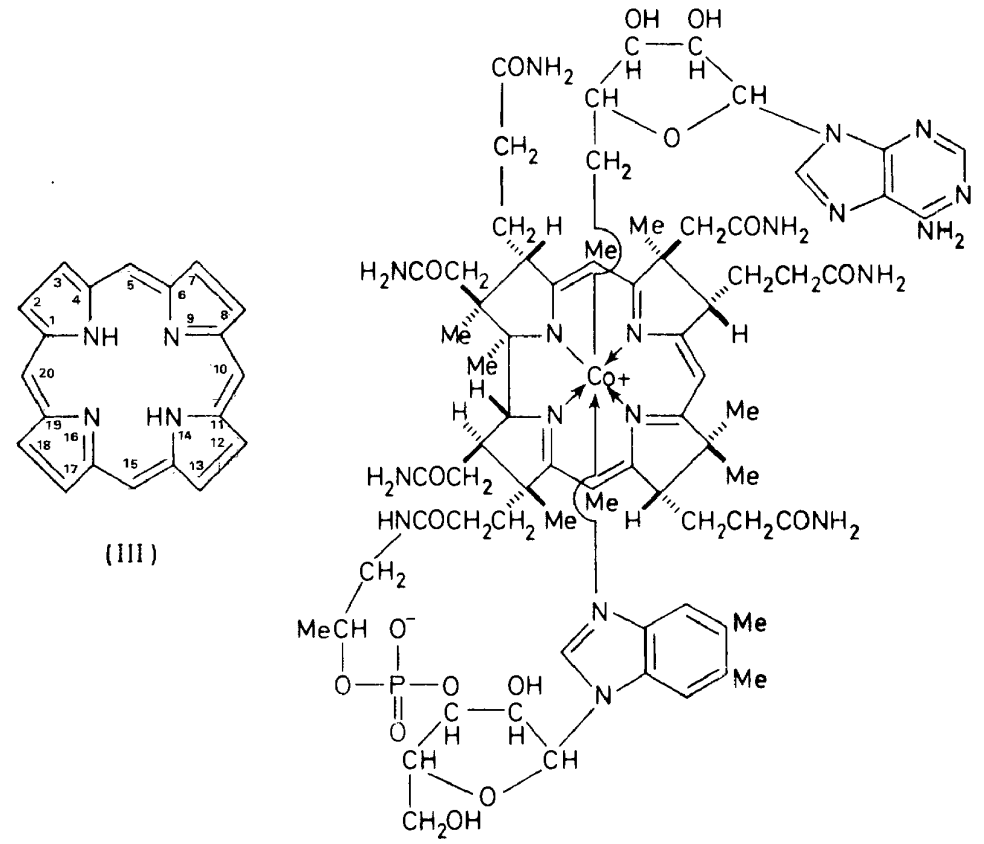

(III)

(IV)

our work, no synthetic routes were available to macrocyclic tetrapyrrolic ring systems containing a direct link between two of the rings. The corrole ring(VI) is intermediate in structure between porphin and corrin and we were able to develop an easy synthesis of corroles by cyclization of the corresponding 1,19-dideoxybiladienes-ac(VII), themselves obtained from readily available pyrrolic intermediates ${ }^{11}$. The cyclization of (VII) to corroles(VI) was effected by irradiation of alkaline solutions in presence of nickel or cobalt salts to yield the metal corroles in high yield. Alternatively in the absence of metal salts, one-electron oxidizing agents yield the free corroles ${ }^{12}$. 
The corrole ring is aromatic as evidenced by the strong Soret band at ca. $400 \mathrm{~nm}$ and the n.m.r. signals of the three meso-protons at $c a . \tau 1$.

However, the formation of a divalent metal corrole(VIII) causes one hydrogen atom to migrate from nitrogen to a carbon of the chromophore (tentatively placed at $\mathbf{C}_{10}$ in VIII) and the resultant complex contains a non-aromatic chromophore. In this respect the metal corroles bear the same relation to porphin as does cyclopentadiene to benzene. Accordingly,<smiles>C1=C(/C=C2/CCC(/C=C3/CCC(C4CCC4)N3)=N2)CC1</smiles>

(V)

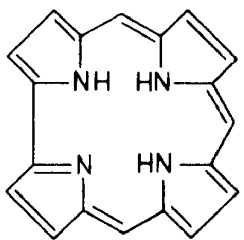

(VI)<smiles>CC(=O)c1[nH]cc(C)c1NC(=O)[O-]</smiles><smiles>CCc1cc[nH]c1Cc1[nH]ccc1CC</smiles>
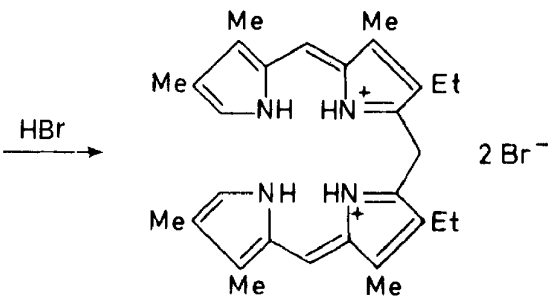

(VII)

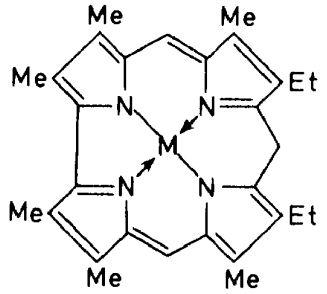

(VIII)

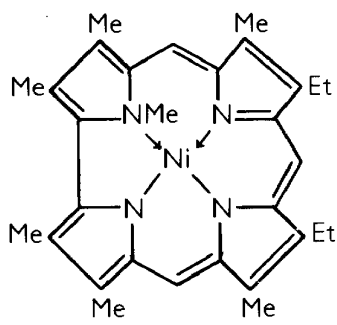

(VIIIA)

Formula VIIIA. Structure of methylated copper corrole [R. Grigg, T. J. King and G. Shelton, Chem. Commun. 56 (1970)].

treatment of nickel corrole with bases readily formed a stable anion which showed a strong Soret band in its visible spectrum indicating a reversion to an aromatic structure. The anion reacted readily with alkyl halides to give crystalline mono-alkylated nickel corroles, the methyl derivative, for example, being obtained in 56 per cent yield ${ }^{13}$. The alkyl derivatives are diamagnetic and the position of alkylation was deduced mainly from n.m.r. studies. The protons of the new methyl group were associated with a singlet at $\tau$ 12.65, the marked upfield shift being the effect of the corrole ring current and providing good evidence that the methyl group was attached directly 
to the nickel atom(IX)*. The three meso-protons of (IX) were represented by a singlet at $\tau 0 \cdot 6$, suggesting an appreciable amount of aromatic character in the molecule, also indicated by a strong Soret band in the visible spectrum. Analysis of the product supported the assigned structure and also suggested, as did the infra-red spectrum, the lack of any water or alcohol in the molecule as a sixth ligand. In order to accommodate an aromatic $18 \pi$-electron ligand, the molecule can be regarded as a derivative of nickel(IV). Analogous ethyl and $n$-propyl derivatives were prepared by similar methods.

Possibly the most interesting of the reactions of the alkyl-nickel corroles is the rearrangement caused by heat. When the methyl-nickel derivative(IX) was heated at $130^{\circ}$ (reflux) for $90 \mathrm{~min}$ in chlorobenzene solution in an atmosphere of nitrogen, it was converted mainly ( 41.5 per cent) to an isomeric compound. Likewise, the ethyl-nickel analogue was found to rearrange at $130^{\circ}$ after $30 \mathrm{~min}$, or, as with the $n$-propyl-nickel analogue, at $80^{\circ}$ after $6 \mathrm{~h}$. The methyl-nickel derivative, however, was unchanged after being heated at $80^{\circ}$ for $8 \mathrm{~h}$, showing that the thermal rearrangement of the larger alkyl groups was more facile than that of methyl. The structure $(\mathrm{X})$ of the rearrangement products was deduced from the n.m.r. spectra of the rearrangement products of three methyl-nickel derivatives of isomeric diethyl-hexamethylcorroles using the ethyl groups as markers. In the 8,12-diethyl series, the rearranged product $(\mathrm{X} ; \mathrm{R}=\mathrm{Me}$ ) contained a gem-dimethyl group and two almost identical ethyl groups, suggesting that the methyl-nickel substituent had not migrated to rings $\mathrm{B}$ or $\mathrm{C}$. In the 2,18-diethyl series, the rearranged product(XI) contained a gem-dimethyl group, indicating that the rearranged methyl group was not at $\mathrm{C}_{2}$; finally in the 3,17-diethyl series, the rearranged product(XII) was shown to contain a gem-ethyl-methyl group and thus the migration of methyl was from the metal to $C_{3}$. In related experiments we have shown that the $\mathrm{C}_{2}$ position is not involved in the rearrangement process and that subsequent rearrangements of alkyl groups from $C_{3}$ to $C_{2}$ do not occur. The intramolecular nature of the alkyl migrations has been established as follows. First, thermolyses of alkyl-nickel 2,18-diethyl-3,7,8,12,13,17-hexamethylcorroles at $130^{\circ} / 90 \mathrm{~min}$ in presence of radical acceptors, e.g. hydroquinone or cumene, caused no decrease in the normal yield of rearranged product. Secondly, thermolysis of a mixture of ethyl-nickel 3,17-diethyl-2,7,8,12,13,18hexamethylcorrole and methyl-nickel 2,18-diethyl-3,7,8,12,13,17-hexamethylcorrole gave a product which showed no 'crossing' of the migrating alkyl group, i.e. the product contained a mixture of a 3,3-diethyl- and a 3,3dimethyl-corrole derivative and none of the 3-ethyl-3-methyl analogue was observed.

In another series, the nickel corrole (VIII) was converted to its anion which was treated with allyl bromide. In this case none of the allyl-nickel derivative was obtained, but instead the main product ( 35 per cent) proved to be the 3-allyl-3-methyl nickel corrole, $(X ; R=$ allyl), i.e. the expected product from the thermolysis of the allyl-nickel compound. In addition neutral diallyl and triallyl derivatives were obtained which appear to contain meso gem-diallyl groupings, e.g. (XIII). The position of the allyl group in the main products

\footnotetext{
* Footnote added April 1970. X-Ray studies have revealed that the methylated copper and nickel corroles contain the additional methyl group as a substituent on the nitrogen atom of ring A of VIII, see previous page.
} 


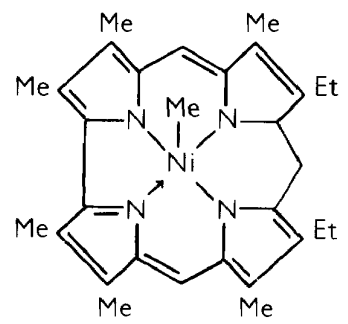

(IX)

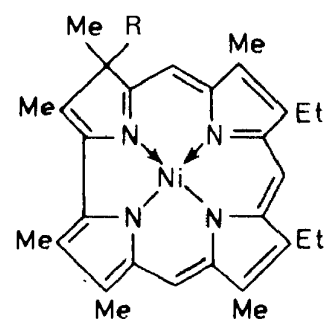

$(X)$

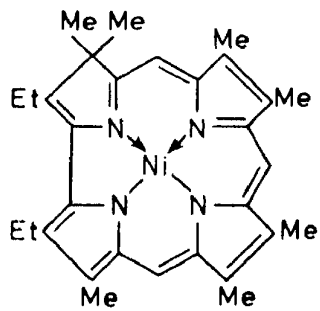

$(X I)$

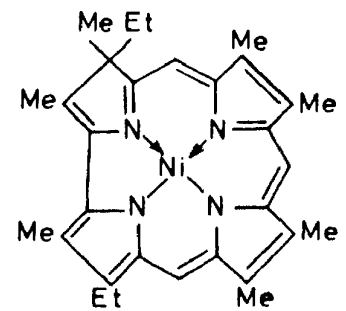

(XII)

(e.g. $X ; R=$ allyl) of the reactions was again established by the technique of using ethyl groups as markers, e.g. nickel 2,18-diethyl-3,7,8,12,13,17-hexamethylcorrole gave a product containing a gem-allyl-methyl substituent, but the isomeric nickel 3,17-diethyl-2,7,8,12,13,18-hexamethylcorrole gave a product(XIV) containing a gem-allyl-ethyl grouping.

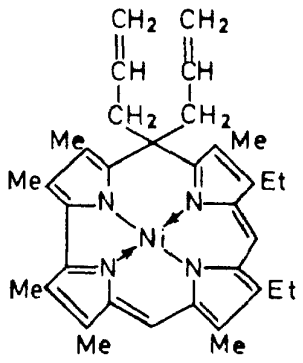

(XIII)

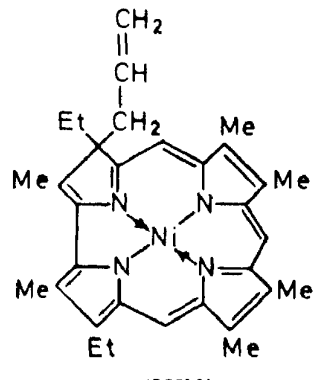

(XIV)

The research on nickel corroles has been extended to other metals. We have shown, for example, that palladium(II) corrole readily forms a crystalline pyridinium salt which on methylation yields a mixture of the methyl-palladium derivative and its rearranged product, the palladium corrole containing a 3,3-dimethyl group. Rearrangement of the former to the latter required 
heating at $180^{\circ} / 90 \mathrm{~min}$, more stringent experimental conditions than are necessary in the nickel series. The anion of copper(II) corrole on methylation gave a methyl-copper complex the structure of which is at present under investigation by $\mathrm{x}$-ray crystallography. However, on heating, the coppermethyl derivative merely reverted to copper corrole and the methyl group was lost. The structure of cobalt corrole is also under investigation; it appears not to be a simple analogue of the nickel and palladium corroles, and alkylation studies are at present in progress.

In the porphin series, the introduction of a metal and the consequent metal-ligand orbital interactions may modify considerably several of the typical porphin properties; for example the effects of metal introduction on the visible spectrum ${ }^{14}$ and the infra-red spectrum ${ }^{15}$ have been subjected to detailed analysis. Likewise as illustrated by studies of meso-substitution, e.g. deuteration ${ }^{16}$, formylation ${ }^{17}$, and meso-oxidation ${ }^{18}$, and reference might be made to $\pi$-interaction between the metal and compounds, such as protein ${ }^{19}$ and unsaturated hydrocarbons ${ }^{20}$.

The explosive rise in interest in metal-carbon bonds was certainly catalysed by the demonstration of the existence of a cobalt-carbon bond in the vitamin $B_{12}$ coenzyme(IV) ${ }^{9}$ and our method ${ }^{21}$ for the facile introduction of alkyl groups directly on to the cobalamin cobalt by reaction of the cobalt(I) species with electrophilic alkylating reagents $\left(\right.$ later $^{22}$ shown to proceed by an $\mathrm{S}_{\mathrm{N}} 2$ mechanism) provides an easy partial synthesis of these compounds. We have also used the same reaction in the porphin series to prepare a range of alkyl-cobalt porphins $(\mathrm{XV})$, compounds which can also be obtained by treatment of cobalt(III) porphins with Grignard reagents ${ }^{23}$. This also finds analogy in the cobalamin series ${ }^{24}$. These reactions have since been used with several related organocobalt compounds ${ }^{25}$, of which the cobaloximes (XVI) of Schrauzer ${ }^{26}$ deserve special mention. Thus the alkylation of cobalt (and iron, see below) complexes can often be achieved by taking advantage of the lower or higher oxidation states of the metal, in contrast to the metal corroles described above where the ligand itself can be readily ionized.

The corroles and porphins differ from most of the other ligands referred to above because of their aromatic nature and this, in consequence of the location of the alkyl substituent within the $\pi$-electron cloud of the ligand, causes a marked shielding effect, and the n.m.r. signal associated with the porphin cobalt-methyl protons appears at $\tau 15 \cdot 15$. Examination of the higher alkyl-cobalt compounds showed that the maximum shielding was exerted on the second carbon atom of the chain. An acetyl-cobalt derivative (acetyl protons at $\tau$ 12.97) was prepared as well as the paramagnetic ethyl- and p-tolyl-iron(III) derivatives. All of the metal-alkyl compounds were readily photolysed and studies of the subsequent fate of the alkyl group have been reported, especially in the cobalamin series ${ }^{27}$.

We have extended the studies of the alkylation of metalloporphins to the use of aliphatic diazo compounds ${ }^{28}$. Reaction of copper(II) octa-ethylporphin with ethyl diazoacetate formed mainly a mixture of the two possible isomers of the chlorin(XVII) formed by addition of the carbene to one of the porphin cross-conjugated double bonds, as well as a small amount of the mesoethoxycarbonylmethylporphin (XVIII). Although no products containing copper-carbon bonds were isolated, there is evidence ${ }^{29}$ to suggest that the 


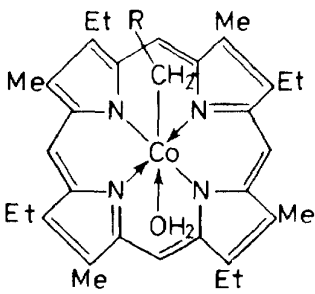

$(\mathrm{XV})$

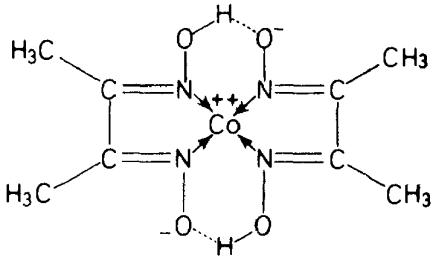

(XVI)

copper is implicated in the reaction with the diazo compounds. However, in the case of cobalt, the experimental evidence for the involvement of the metal is more definite. We had already shown ${ }^{21}$ that in the cobalamin series, reaction of the cobalt(I) derivative (vitamin $\mathbf{B}_{12 \mathrm{~s}}$ ) with diazomethane gave methylcobalamin. However, reaction of cobalt(II) octaethylporphin, or preferably the cobalt(II) pyridino-bromo derivative of the porphin, with ethyl diazoacetate gives a crystalline $\mathrm{N}_{4}$ adduct which contains cobalt(III) (n.m.r.), an ester grouping (i.r.), and a modified porphin ring (visible spectrum), the analysis of which indicates that it is an adduct of the cobalt porphin and ethoxycarbonylcarbene. A similar but more stable product has also been obtained from benzoylphenyldiazomethane. Several reagents, e.g. sodium hydroxide, cause the adduct to revert to the original cobalt(II) porphin indicating that the carbene is not a substituent on the porphin ring. Irradiation of the adduct gives a complex mixture of products, of which cobalt(II) octaethylporphin and an ethoxycarbonylmethyl substitution product (possibly XVIII; Co ${ }^{\text {II }}$ complex) are major constituents. Work on these compounds is still actively in progress but as a working hypothesis we are considering the adducts as carbene-cobalt(III) complexes derived from an unsymmetrical ring system as in $(\mathrm{XIX})^{30 *}$. Carbene-cobalt complexes have not been reported previously and indeed most of the carbene-metal complexes described contain substituent electron-donating groups on the carbene $^{32}$.

A structural feature of the corrins of the cobalamin series in the $\mathrm{C}_{1}$ methyl group at the direct linkage between two of the pyrrolic rings and this angular substituent must necessarily break any conjugated system. In order to prepare such macrocyclic compounds, we first examined the possibility of cyclizing 1,19-dimethyl-1,19-dideoxybiladienes-ac(XX) recognizing that in order to keep the termini in juxtaposition it would be necessary to use a metal complex. Unfortunately our first choice ${ }^{33}$ was copper which gave us a new synthesis of porphins, one of the terminal methyl groups forming the new meso bridge $\left(\mathrm{C}_{20}\right)$, and the other being expelled. This porphin synthesis has found some synthetic application ${ }^{34}$. However, when an alkaline solution of the 1,19-dimethyl-1,19-dideoxybiladiene was aerated in presence of nickel or cobalt ions, a cationic macrocyclic system, 1,19-dimethyltetradehydrocorrin(XXI), was readily obtained in the form of the crystalline salts of its metal complexes ${ }^{35}$. Of the properties of these salts, the trans disposition of the 1- and 19-methyl substituents has been proved by the resolution of the

* Footnote added April 1970. The ring system depicted in (XIX) is incorrect and it now seems that the products retain the porphin chromophore. 


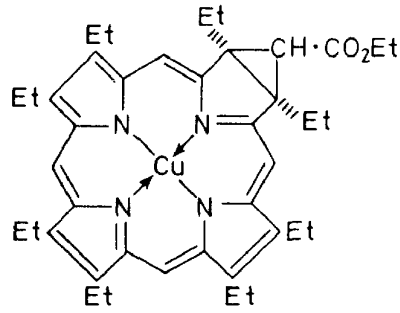

(XVII)

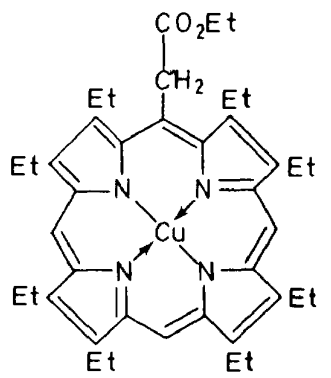

(XVIII)

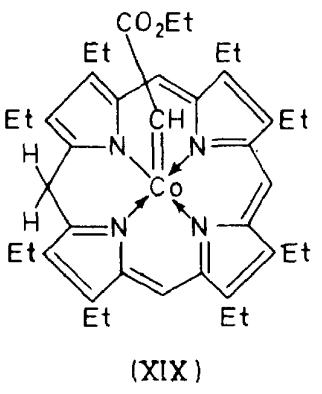

D-camphorsulphonates ${ }^{36}$, and the stepwise hydrogenation of the nickel 1,19-dimethyltetradehydrocorrin salts has yielded the corresponding crystalline tri-, and didehydrocorrin salts ${ }^{37}$. Vigorous hydrogenation of the tetradehydrocorrins has given non-crystalline nickel corrins ${ }^{38}$.

Meanwhile the tetradehydrocorrins containing only one angular methyl group(XXII) were synthesized by cyclization of alkaline solutions of 19bromo-1-methylbiladienes-ac(XXIII) in presence of nickel ions ${ }^{39}$. It is pertinent that when the salts of 19-bromo-1-methylbiladienes-ac were heated alone for a short time in boiling $o$-dichlorobenzene ${ }^{40}$, or even in certain cases by treatment of a pyridine solution with dimethyl sulphoxide ${ }^{41}$, porphins were obtained, often in high yield, and a variety of unsymmetrically substituted porphins has been prepared in this manner ${ }^{42}$. The presence of the metal therefore completely changes the course of the cyclization, and either the porphin or corrin ring systems can be obtained at will. The 1-alkyltetradehydrocorrins were found to be particularly susceptible to protonation ${ }^{39}$ or alkylation ${ }^{43}$ at $\mathrm{C}_{19}$ to yield the salts of the 1,19-dialkyltetradehydrocorrins referred to above. A further example of the migration of alkyl groups in these macrocycies was encountered when the nickel 1-alkyltetradehydrocorrins were heated, the products being the same nickel 3,3-dialkylcorroles (e.g. X), as were observed in the thermolytic rearrangements of the methylnickel corroles. By use of ethyl groups as markers and taking in to account the greater migratory aptitude of ethyl compared with methyl, it was shown that the $C_{1}$ substituent moved first to $C_{2}$ and then to $C_{3}$ by a concerted mechanism ${ }^{44}$. In extensions of these observations it was shown that $C_{1}$ allyl groups would undergo the rearrangement to $C_{3}$ particularly easily, and 
that $\gamma \gamma$-dimethylallyl groups were not inverted in the course of the rearrangement. Moreover, ethoxycarbonyl angular substituents could also be rearranged from $\mathrm{C}_{1}$ to $\mathrm{C}_{3}$ and these interesting migrations also proceeded under experimental conditions much milder than those required for the rearrangement of alkyl groups.

In another example, nickel 1-ethoxycarbonyl-19-allyltetradehydrocorrin perchlorate (XXIV), the ester group has been shown to migrate to $\mathrm{C}_{3}$, and the allyl group to a meso position, probably $\mathrm{C}_{15}$, on moderate heating ${ }^{44}$. This contrasts with the thermolytic rearrangement of the nickel 1,19-dialkyltetradehydrocorrin salts which yield porphins. Details of this rearrangement

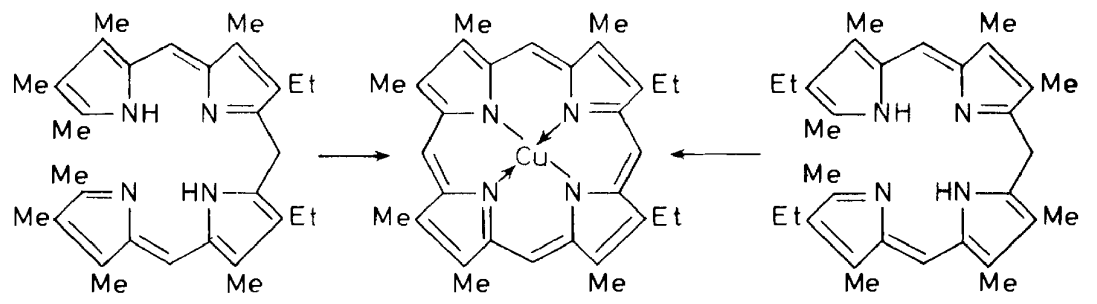

$(X X)$

$$
\text { Reagent: } \mathrm{Cu}(\mathrm{OAC})_{2} \text { in } \mathrm{MeOH}
$$

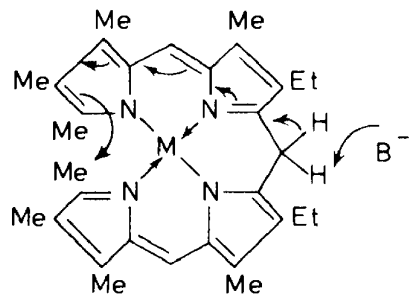

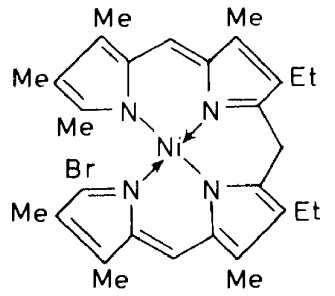

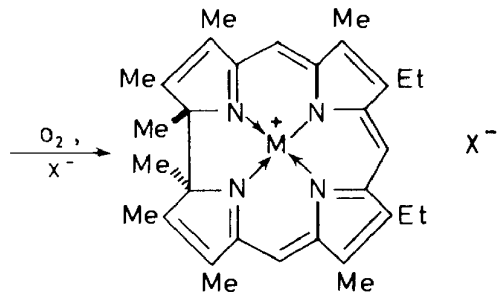

$(X X I)$

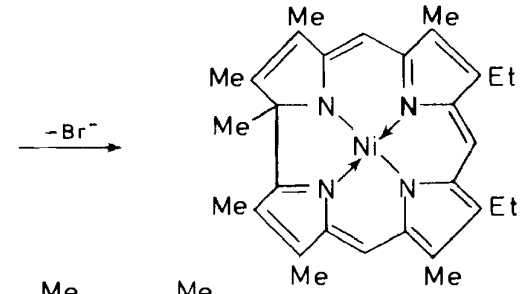

(XXII)

(XXII)

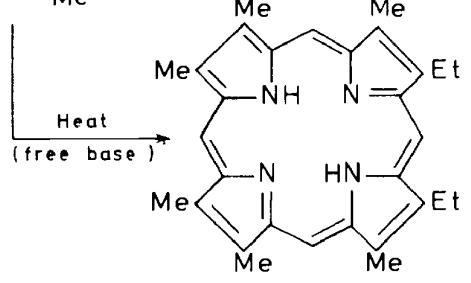




\section{A. W. JOHNSON}

have also been elucidated ${ }^{45}$ (e.g. XXI $\rightarrow$ XXV $\rightarrow \overline{X X V I} \rightarrow$ XXVII), the appearance or otherwise of a meso substituent in the final product depending on the nature of the anion. Perchlorate appeared to be unique in yielding meso-substituted porphins.
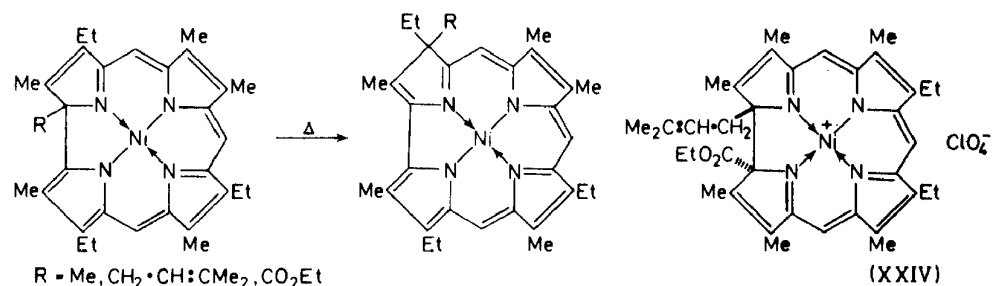

$\mathrm{R}=\mathrm{Me}, \mathrm{CH}_{2} \cdot \mathrm{CH}: \mathrm{CMe}_{2}, \mathrm{CO}_{2} \mathrm{Et}$
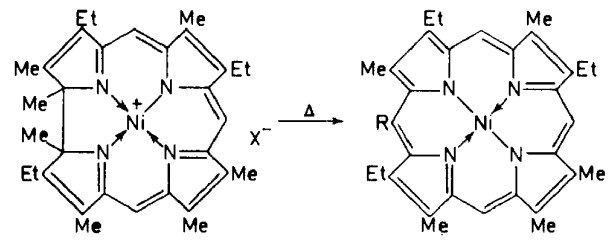

(A) $X$ - halide

$\mathrm{R}=\mathrm{H}$

(B) $\mathrm{X}-\mathrm{ClO}_{6}$

$\mathrm{R}=\mathrm{Me}$
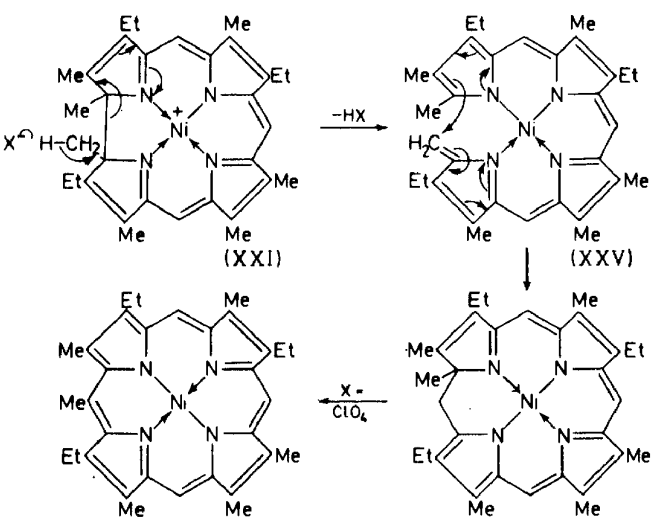

In spite of much accumulated knowledge on methods of preparation and properties of cobalt-carbon bonds there are several features of the biochemical mode of action of the vitamin $B_{12}$ coenzyme and related corrinoids ${ }^{46}$ which are not yet fully understood. The reactions in which the corrinoid coenzymes are involved are of two types: the first are transmethylations and utilize methylcobalamin rather than the 5 '-deoxyadenosyl derivative. The particular reactions involve the formation of methionine, acetic acid and methane. The overall reaction in the formation of methionine from homocysteine is the transfer of a methyl group from a tertiary amine $\left(\mathrm{N}_{5}\right.$-methyltetrahydrofolate) to cobalt (i.e. to form methylcobalamin) and then to the thiol group of homocysteine (Scheme 1). Transference of methyl groups from nitrogen to cobalt has not been observed in the laboratory and the demonstration that S-adenosylmethionine is required as an activator for the biosynthesis of methylcobalamin is therefore of special interest ${ }^{47}$. 


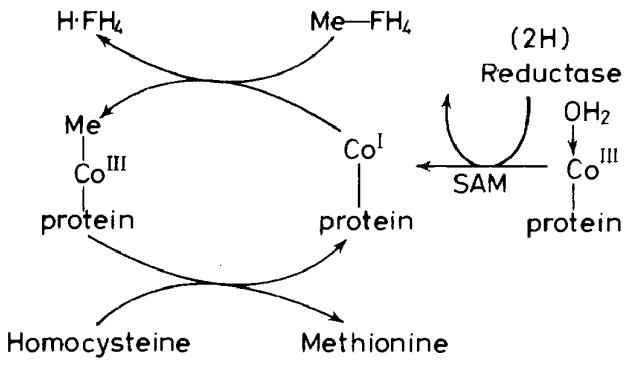

SAM $=S$ - Adenosylmethionine

For the formation of methane, the coenzyme (Factor III) involved ${ }^{48}$ incorporates 5-hydroxybenziminazole rather than 5,6-dimethylbenziminazole (cf. IV) and the cobalt-methyl derivative is the intermediate which undergoes reduction to yield methane. It has been shown that a variety of cobalt-methyl derivatives can be reduced by this biological system which therefore displays a remarkable lack of selectivity ${ }^{49}$. Hydrogenation of methyl-cobalamin also yields methane ${ }^{50}$, but the biological reduction, for which the presence of ATP is essential, requires a large negative potential and still presents difficulties regarding the precise mechanism of the reaction ${ }^{2}$. Likewise the mechanism of the reaction of methylcobalamin with carbon dioxide has not been fully elucidated and the possible intermediacy of carboxymethylcobalamin ${ }^{51}$ has not been established.

A second group of biochemically important reactions is controlled by 5 -adenosylcobalamin itself and involves 1,2-migrations of hydrogen, probably as hydride, and other groups simultaneously. The rearrangements are typified by the dehydration of propanediol to propionaldehyde ${ }^{52}$, the isomerization of glutamic acid to $\beta$-methylaspartic acid $^{54}$, and the isomerization of the 6-amino group of $\beta$-lysine to the 5-position ${ }^{55}$.

$\mathrm{CH}_{3} \cdot \mathrm{CHOH} \cdot \mathrm{CH}_{2} \mathrm{OH} \rightarrow\left[\mathrm{CH}_{3} \cdot \mathrm{CH}_{2} \cdot \mathrm{CH}(\mathrm{OH})_{2}\right] \rightarrow \mathrm{CH}_{3} \cdot \mathrm{CH}_{2} \cdot \mathrm{CHO}$

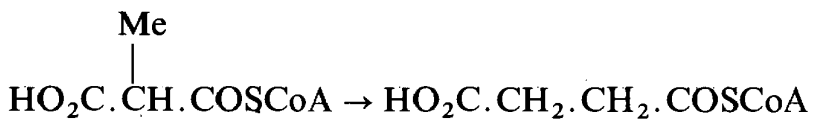

$\mathrm{HO}_{2}$ C. CH. $\mathrm{CH}_{2} \cdot \mathrm{CH}_{2} \cdot \mathrm{COSCoA} \rightarrow \mathrm{HO}_{2}$ C. CH. CHMe.COSCoA<smiles>NCCCCN</smiles>

$\mathrm{HO}_{2} \mathrm{C} . \mathrm{CH}_{2} \cdot \underset{\mathrm{NH}_{2}}{\mathrm{CH}} \cdot \mathrm{CH}_{2} \cdot \mathrm{CH}_{2} \cdot \mathrm{CH}_{2} \mathrm{NH}_{2} \rightarrow \mathrm{HO}_{2} \mathrm{C} . \mathrm{CH}_{2} \cdot \underset{\mathrm{NH}_{2}}{\mathrm{CH}} \cdot \underset{\mathrm{NH}_{2}}{\mathrm{CH}_{2}} \cdot \underset{\mid}{\mathrm{CHMe}}$ 


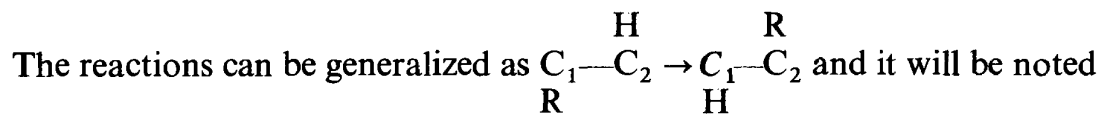

that the carbon atoms $\mathrm{C}_{1}$ and $\mathrm{C}_{2}$ are not necessarily activated by adjacent functional groups. No exchange of hydrogen occurs with the solvent and the reactions are intramolecular and stereochemically defined. Thus inversion of configuration at the carbon to which the hydrogen migrates has been established for propanediol dehydration ${ }^{56}$ and glutamate isomerization ${ }^{57}$, but with retention in the methylmalonyl-coenzyme $\mathrm{A}$ isomerization ${ }^{58}$. The use of labelled substrates ${ }^{59}$ has shown that although the migrating hydrogen does not exchange with solvent, it exchanges with the coenzyme and also that the hydrogen atoms of the $5^{\prime}$-methylene group of the coenzyme (i.e. Co- $-\mathrm{CH}_{2}$ ) can be transferred to the product (up to 32 per cent of tritium transferred to succinic acid from coenzyme). Finally there is evidence for the existence of an intermediate containing at least two and probably three equivalent hydrogen atoms at $\mathrm{C}_{5}$ of the sugar, and for at least one of these hydrogens being derived from the substrate.

Experimental evidence that the substrate becomes attached to the cobalt is still lacking although this is usually invoked in the various proposals for the mechanism of these reactions which can be summarized as shown below ${ }^{60}$ (or with variants ${ }^{61}$ ) in the specific case of the propane-1,2-diol rearrangement:
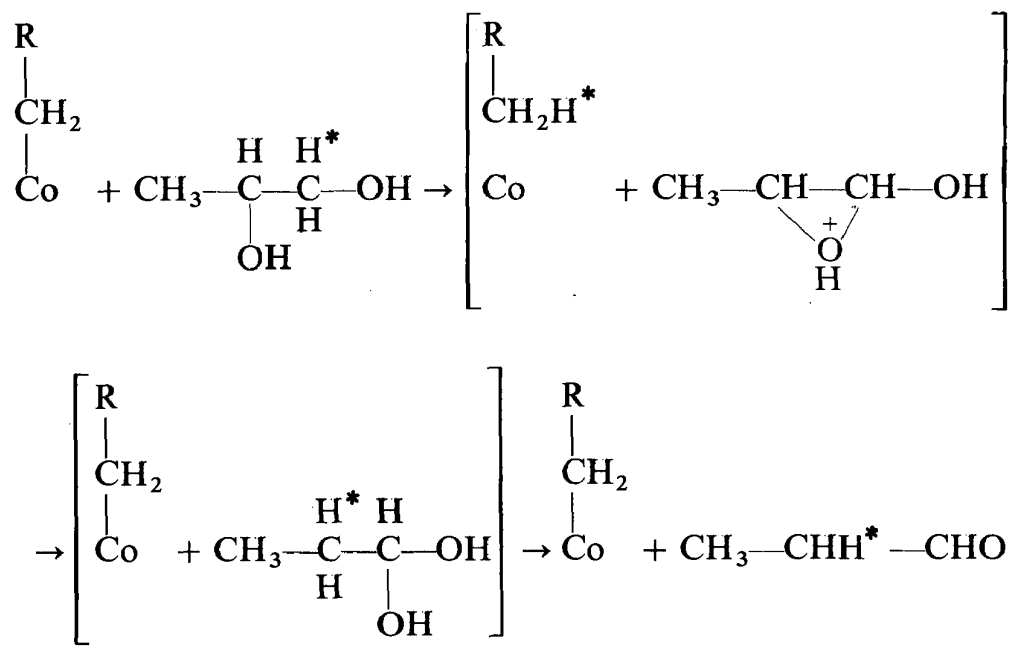

A somewhat similar scheme has been proposed for the mechanism of the reduction of ribonucleoside triphosphates to $2^{\prime}$-deoxyribonucleoside triphosphates which is controlled by the ribonucleotide reductase, an enzyme system which is dependent on $5^{\prime}$-deoxyadenoxylcobalamin. In this case mechanistic studies have shown that there is a transfer of hydrogen between the aqueous solvent and the $5^{\prime}$-methylene-cobalt group of the coenzyme and thus to the deoxyribonucleotide product. The course of the reaction is summarized in Scheme $2^{62}$.

Thus the biochemical reactions controlled by the vitamin $\mathrm{B}_{12}$ coenzyme 


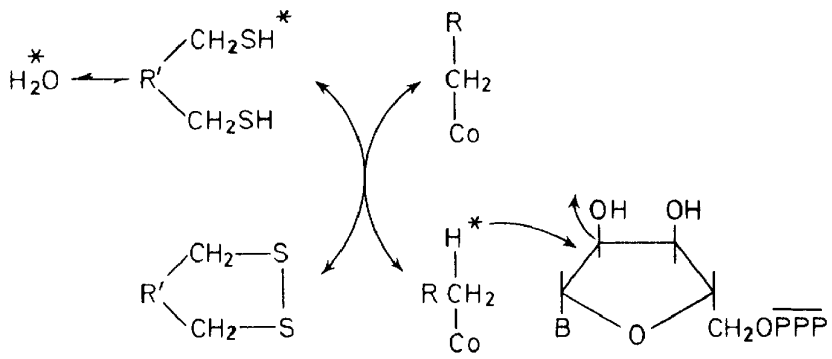

still pose several questions of mechanism, but these are being actively studied by many research groups at the present time.

Much of what I have said has been the research results of colleagues both at Nottingham and at Sussex and I acknowledge the privilege of acting as their spokesman.

\section{REFERENCES}

${ }^{1}$ H. Fischer and H. Orth, Die Chemie des Pyrrols, Vols. I, IIi and IIii. Leipzig (1934-40).

2 R. J. P. Williams, Roy. Inst. Chem. Reviews, 1, 13 (1968).

3 E. B. Fleischer and N. Sadasivan, Chem. Commun. 159 (1967).

E. B. Fleischer and D. Lavallee, J. Amer. Chem. Soc. 89, 7132 (1967).

4 E. B. Fleischer, R. Thorp and D. Venerable, Chem Commun. 475 (1969).

5 N. Sadasivan and E. B. Fleischer, J. Inorg. Nuclear Chem. 30,591 (1968).

6 E. B. Fleischer and A. Laszlo, Inorg. Nuclear Chem. Lett. 5, 373 (1969).

D. B. Boylan and M. Calvin, J. Amer. Chem, Soc. 89, 5472 (1967).

B A. E. Kane, R. G. Yalman and M. E. Kenney, Inorg. Chem. 7, 2588 (1968).

9 P. G. Lenhert and D. C. Hodgkin, Nature, London, 192, 937 (1961).

P. G. Lenhert. Proc. Roy. Soc. A, 303, 45 (1968).

10 D. C. Hodgkin, A W. Johnson and A R. Todd, Chem. Soc., London, Spec. Publ. No. 3, 109 (1955).

11 A. W. Johnson and I. T. Kay, J. Chem. Soc. 1620 (1965).

12 D. Dolphin, A. W. Johnson, J. Leng and P. Van den Broek, J. Chem. Soc. C, 880 (1966).

13 R. Grigg, A. W. Johnson and G. Shelton, Chem. Commun. 1151 (1968).

14 A. H. Corwin, A. B. Chivvis, R. W. Poor, D. G. Whitten and E. W. Baker, J. Amer. Chem. Soc. 90,6577 (1968).

15 L. J. Boucher and J. J. Katz, J. Amer. Chem. Soc. 89,1340 (1967).

G. Vanderkooi and E. Stotz, J. Biol. Chem. 240, 2418 (1965).

16 R. C. Dougherty, H. H. Strain and J. J. Katz, J. Amer. Chem. Soc. 87, 104 (1965).

17 A. W. Johnson and D. Oldfield, J. Chem. Soc. 794 (1966). H. H. Inhoffen, J. H. Fuhrhop, H. Voigt and H. Brockmann Jr, Liebigs Annalen, 695, 133 (1966).

18 R. Bonnett and M. J. Dimsdale, Tetrahedron Lett. 731 (1968).

19 W. S. Caughey, H. Eberspaecher, W. H. Fuchsman, S. McCoy and J. O. Alben, Ann. N.Y. Acad. Sci. 153, 722 (1969).

20 M. Tsutsui, R. A. Velapoldi, L. Hoffman, K. Suzuki and A. Ferrari, J. Amer. Chem. Soc. 91, 3337 (1969).

21 A. W. Johnson, L. Mervyn, N. Shaw and E. Lester Smith, Nature, London, 192, 1175 (1962); J. Chem. Soc. 4146 (1963).

K. Bernhauer, O. Müller and G. Müller, Biochem. Z. 336, 102 (1962).

O. Müller and G. Müller, Biochem. Z. 336, 229 (1962). 


\section{A. W. JOHNSON}

22 G. N. Schrauzer and E. Deutsch, J. Amer. Chem Soc. 91, 3341 (1969).

23 D. A. Clarke, D. Dolphin, R. Grigg, A. W. Johnson and H. A. Pinnock, J. Chem. Soc. C, 881 (1968).

${ }^{24}$ F. Wagner and K. Bernhauer, Ann. N.Y. Acad. Sci.112, 580 (1962).

25 P. Day, H. A. O. Hill and M. G. Price, J. Chem. Soc. A, 90 (1968).

G. Costa and G. Mestroni, Tetrahedron Lett., 4005 (1967).

G. Costa, G. Mestroni, G. Tauzher and L. Stefani, J. Organomet. Chem. 6, 181 (1966).

E. Ochiai, K. M. Long, C. R. Sperati and D. H. Busch, J. Amer. Chem. Soc. 91, 3201 (1969).

${ }^{26}$ G. N. Schrauzer, Accts Chem. Research, 1, 97 (1968).

27 D. Dolphin, A. W. Johnson and R. Rodrigo, J. Chem. Soc. 3186 (1964).

R.-H. Yamada, T. Kato, S. Shimizu and S. Fukui, Biochim. Biophys. Acta, 97, 353 (1965).

R.-H. Yamada, S. Shimizu and S. Fukui, Biochim. Biophys. Acta, 124, 195 and 197 (1966). H. P. C. Hogenkamp, Biochemistry, 5, 417 (1966).

G. N. Schrauzer, J. W. Sibert and R. J. Windgassen, J. Amer. Chem Soc. 90, 6681 (1968).

28 H. J. Callot and A. W. Johnson, Chem. Commun. 749 (1969).

29 W. R. Moser, J. Amer. Chem. Soc. 91, 1135 and 1141 (1969).

${ }^{30}$ The ligand depicted here is a dehydrophlorin, phlorin ${ }^{31}$ being a dihydroporphin, isomeric with chlorin.

31 R. B. Woodward, Industr. Chim. Belg. 27, 1293 (1962).

32 E. O. Fischer and E. Offaus, Chem. Ber. 102, $2449(1969)$ and earlier papers in this series.

33 A. W. Johnson and I. T. Kay, J. Chem. Soc. 2418 (1961).

R. Grigg, A. W. Johnson, R. Kenyon, V. B. Math and K. Richardson, J. Chem. Soc. C, 176 (1969).

34 G. M. Badger, R. L. N. Harris and R. A. Jones, Austral. J. Chem. 17, 1013 (1964).

P. S. Clezy and A. J. Liepa, Chem. Commun. 767 (1969).

35 D. Dolphin, R. L. N. Harris, J. L. Huppatz, A. W. Johnson and I. T. Kay, J. Chem. Soc. C, 30 (1966).

36 P. Van den Broek and A. W. Johnson, published work, University of Nottingham.

37 I. D. Dicker and H. Pinnock, unpublished work, University of Nottingham.

${ }^{38}$ R. Grigg, A. W. Johnson and P. Van den Broek, Chem Commun. 502 (1967).

39 D. A. Clarke, R. Grigg, R. L. N. Harris, A. W. Johnson, I. T. Kay and K. W. Shelton, J. Chem. Soc. C, 1648 (1967).

40 R. L. N. Harris, A. W. Johnson and I. T. Kay, J. Chem. Soc. C, 22 (1966).

${ }^{41}$ P. Bamfield, R. L. N. Harris, A. W. Johnson, I. T. Kay and K. W. Shelton, J. Chem. Soc. C, 1436 (1966).

42 P. Bamfield, R. Grigg, A. W. Johnson and R. W. Kenyon, J. Chem. Soc. C, 1259 (1968).

43 R. Grigg, A. W. Johnson and K. W. Shelton, J. Chem. Soc. C, 1291 (1968).

${ }^{44} \mathrm{M}$. Smith, unpublished work, University of Nottingham.

${ }_{45}$ R. Grigg, A. W. Johnson, K. Richardson and K. W. Shelton, J. Chem. Soc. C, 655 (1969).

${ }^{46}$ H. A. Barker, Biochem. J. 105, 1 (1967).

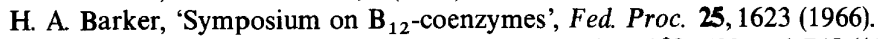

47 R. Taylor and H. Weissbach, Arch. Biochem. Biophys. 129, 728 and 745 (1969).

48 J. M. Wood and R. W. Wolfe, Biochemistry, 5, 3598 (1966).

J. M. Wood, F. S. Kennedy and R. S. Wolfe, Biochemistry, 7, 1707 (1968).

49 B. C. McBride, J. M. Wood, J. W. Sibert and G. N. Schrauzer, J. Amer. Chem. Soc. 90,5276 (1968).

50 D. Dolphin, A. W. Johnson and R. Rodrigo, J. Chem. Soc. 3186 (1964).

51 L. Ljungdahl, E. Irion and H. G. Wood, Fed. Proc. 25, 1642 (1966).

52 R. H. Abeles and R. A. Frey, Fed. Proc. 25, 1639 (1966).

R. A. Frey and R. H. Abeles, J. Biol. Chem. 241, 2732 (1966).

53 P. Lengyel, R. Mazumda and S. Ochoa, Proc. Nat. Acad. Sci., Wash. 46, 1312 (1960).

54 H. A. Barker, H. Weissbach and R. D. Smyth, Proc. Nat. Acad. Sci., Wash. 44, 1093 (1958).

55 T. C. Stadtmann and L. Tsai, Biochem. Biophys. Res. Commun. 28, 920 (1967).

56 J. Refey, A. Umani-Ronchi and D. Arigoni, Experientia, 22, 72 (1966).

B. Zagalak, P. A. Frey, G. L. Karabatsos and R. H. Abeles, J. Biol. Chem. 241, 3028 (1966).

57 M. Sprecher, R. L. Switzer and D. B. Sprinson, J. Biol. Chem. 241, 864 (1966).

58 M. Sprecher, M. J. Clark and D. B. Sprinson, J. Biol. Chem. 241,872 (1966).

59 R. H. Abeles and B. Zagalak, J. Biol. Chem. 241, 1245 (1966).

P. A. Frey and R. H. Abeles, J. Biol. Chem. 241, 2432 (1966).

J. Riley and D. Arigoni, Experientia, 22, 783 (1966). 


\section{TRANSITION METAL COMPLEXES}

60 W. W. Miller and J. H. Richards, J. Amer. Chem. Soc. 91, 1498 (1969).

${ }^{61}$ Y. Tamao, M. Morikawa, S. Shimizu and S. Fukui, Biochem. Biophys. Acta, 151, 260 (1968).

${ }^{62}$ H. P. C. Hogenkamp, R. K. Ghambeer, C. Brownson, R. L. Blakley and E. Vitols, J. Biol. Chem. 243, 799 (1968). 